\title{
A PROBLEMÁTICA DA ZONA ECONÔMICA EXCLUSIVA: VAMOS PERDER AS 200 MILHAS?*
}

\author{
Vicente Marotta Rangel \\ Professor Catedrático aposentado Faculdade de Direito da USP
}

Da análise do tema que me é consignado, infere-se que a interrogação nele inserida fica na dependência das premissas que se estabeleçam sobre a denominada "problemática da zona econômica exclusiva" Quanto ao conteúdo mesmo da pergunta, parece-nos comportar diferentes interpretações, de modo que a resposta pertinente há de resultar da opção por uma dessas interpretações, como se dirá a seguir.

2. Ainda com relação ao tema proposto, cabe precisar, que a faixa das duzentas milhas paralela ao litoral do Estado costeiro não abrange, como se sabe, a área da zona econômica exclusiva senão também a área do mar territorial desse mesmo Estado. Pode-se também nela inserir-se a zona contígua, assim como a plataforma continental. Pode-se compreender, todavia, se haja feito referência somente à zona econômica exclusiva e a sua problemática. É que a noção, a natureza e o regime do mar territorial são tradicionais, configurados desde a Idade Média, sedimentados em doutrina e prática até hoje, em grande parte preservados. Embora de origens menos remotas, pois derivam respectivamente de 1930 a de 1945 , a zona contígua e a plataforma continental possuem regulamentação suficientemente aclarada. O mesmo não se poderia dizer da zona econômica exclusiva, cuja noção, natureza e regime poderiam demandar ainda maior precisão, em grande parte por terem sido definidos em época bastante recente, mais precisamente na Convenção das Nações Unidas sobre o Direito do Mar, assinada a 10 de dezembro de 1982 e posta em vigor a 16 de novembro do ano passado.

3. Remonta, pelo menos, ao século XIII a distinção clássica entre dois espaços marítimos: o alto-mar, de um lado, cousa comum a todos os Estados, segundo ficou assentado no curso do século XVII, regido em grande parte pelo princípio da liberdade dos mares; e de outro lado, o mar territorial, considerado como parte integrante do território do Estado costeiro a cuja soberania se encontra

* Conferência proferida a convite da Sociedade Brasileira para o Progresso da Ciência, em julho de 1995, em São Luís do Maranhão. 
sujeito, soberania essa limitada apenas pelo reconhecimento, mediante a observância de determinadas condições, do direito de passagem inocente de navios estrangeiros. Quanto ao mar territorial, apenas uma dúvida tinha subsistido ao longo dos séculos, a concernente à determinação de sua largura, controvérsia essa que o tratado recente das Nações Unidas sobre o direito do mar dirimiu ao estipular ser essa largura de doze milhas marítimas.

4. Tal dúvida esteve intimamente associada com o chamado processo de revisão do direito do mar, que foi desencadeado, logo após o término da Segunda Grande Guerra, pelas proclamações do presidente Harry Truman, dos Estados Unidos, datadas de 28 de agosto de 1945, sobre recursos naturais da plataforma continental e sobre zonas de conservação dos recursos marinhos em certas áreas do alto-mar adjacentes ao mar territorial. A inovação dessas proclamações, sobretudo a primeira delas, constitui em modificar a delimitação tradicional entre mar territorial e alto-mar, que se fazia não apenas em relação às águas marítimas senão também em relação ao solo e subsolo cobertos por essas águas. A noção jurídica de plataforma continental passou a significar que o território terrestre do Estado costeiro poderia estender-se além do território marítimo desse mesmo Estado.

5. Segundo as proclamações do presidente Truman, o regime da plataforma continental, cuja fronteira interior deveria coincidir com o término do mar territorial, não importaria em modificação do regime de águas a essa plataforma superjacentes. A tal modelo ajustaram-se vários Estados, inclusive o Brasil, nos termos do Decreto n. 28.840, de 08 de novembro de 1950. Alguns Estados da América Latina, manifestando inconformidade com essa diretriz, passavam a referirse a uma distância de duzentas milhas marítimas, prioridade reconhecida à Declaração do Chile, anunciada apenas dois anos posteriores à Declaração dos Estados Unidos. Tal distância na área do Pacífico Sul (Peru, Equador, Chile), significava uma forma de compensação da carência de plataforma continental geográfica ou geológica, enquanto na área do Atlântico Sul (Argentina e Uruguai) indicava, com o nome então mais divulgado de mar epicontinental, a dimensão aproximada alcançada pelas águas superjacentes à plataforma continental.

Sem que esse fosse o propósito almejado, as proclamações estadunidenses acabaram provocando uma verdadeira revolução nas normas clássicas do direito do mar, a qual se acentuou com o progresso tecnológico e a incidência de diferentes fatores: econômico, geológico, estratégico-militar, científico e político. Exemplo de oposição a essas normas, foi a Declaração-conjunta sobre 
Zona Marítima, subscrita em 1952 pelo Chile, Equador e Peru, a qual afirmava jurisdição desses Estados sobre essa Zona, cuja largura se estimava em duzentas milhas, mas cuja natureza permanecia indefinida.

6. Na primeira Conferência das Nações Unidas sobre o direito do mar (Genebra, 1958) celebraram-se quatro convenções internacionais. Nela não houve êxito na determinação da largura do mar territorial e na determinação da extensão e da natureza de zonas de pesca adjacentes ao litoral do Estado costeiro. Malogrou também, nesses tópicos, a segunda Conferência (Genebra, 1960). A vinculação a essas convenções importava, todavia, em renúncia à ampliação da largura do mar territorial além de doze milhas marítimas. Outrossim, sem estabelecer determinação precisa de fronteira exterior de plataforma continental, a convenção respectiva ensejava a apropriação gradual dos recursos dos fundos oceânicos por parte dos países tecnologicamente desenvolvidos. Cresceu, por outro lado, o número de Estados que se tornaram independentes a partir da década de 60 e que se consideravam desvinculados das convenções de Genebra de 1958. Temia-se, ademais, a utilização dos fundos oceânicos para fins militares. As legislações dos Estados se revelavam discrepantes entre si, assim como em relação às normas internacionais marítimas. Tais foram motivos que determinaram a convocação da terceira Conferência das Nações Unidas sobre o direito do mar que, após negociações intensivas durante nove anos (1973-1982), aprovou a Convenção de Montego Bay, atualmente em vigor.

7. Quanto à problemática da zona econômica exclusiva, cabe notar que, no curso da Conferência, configuravam-se diferentes grupos de Estados. Havia os negadores de jurisdição do Estado costeiro sobre recursos naturais das águas situadas além-do-mar territorial, cuja extensão máxima admitida seria de doze milhas. Esse primeiro grupo abrangia cerca de 60 Estados e dele faziam parte Estados mediterrâneos (28), Estados costeiros de mares fechados ou semifechados (26), além de alguns poucos Estados propriamente costeiros, desenvolvidos tecnologicamente na indústria da pesca, verbi gratia Japão e Grã-Bretanha. A maior parte da Conferência, cerca de 100, num total de 160 Estados, admitia jurisdição do Estado costeiro sobre recursos naturais até a distância de duzentas milhas. Quanto à natureza dessa área marítima, havia discrepância entre duas correntes: os territorialistas e os zonistas. Os territorialistas preconizavam a extensão do mar territorial até essa distância mas eram minoria, no máximo 28 Estados, dos quais somente cinco eram latino-americanos: Brasil, Peru, Equador, Uruguai e El 
Salvador. Predominavam numericamente os zonistas, ou seja, os que entendiam ser necessário constituir-se na faixa marítima, que se estende entre a $12^{\mathrm{a}}$ e a $200^{\mathrm{a}}$ milhas marítimas, numa área jurídica nova, que sem seu prolongamento do mar territorial do Estado costeiro, permitiria a este exercer determinados direitos, sobretudo os relativos à exploração dos recursos naturais.

O alto-mar se situaria somente após a distância da $200^{\mathrm{a}}$ milha marítima. A nova área alcançou a denominação de zona econômica exclusiva. $\mathrm{Na}$ disputa que entre si mantiveram territorialistas e zonistas, não apenas estes prevaleceram numericamente, senão também contaram com o apoio dos que desejavam circunscrever a jurisdição do Estado costeiro sobre recursos naturais apenas ao respectivo mar territorial. Restava aos territorialistas, no que lograram êxito, contribuir para que a zona econômica exclusiva se assemelhasse, o mais possível, ao mar territorial, sem embargo do reconhecimento final de serem essas duas áreas marítimas distintas entre si.

8. Comecemos por indagar em que consistem a zona econômica exclusiva, a sua natureza, os direitos que nela exercem o Estado costeiro e terceiros Estados, tal como ficou estabelecido na Convenção das Nações Unidas sobre o direito do mar.

A zona econômica exclusiva não é mar territorial mas também não é alto-mar. Ela tem natureza e regime específicos. Situa-se além do mar territorial, mas não poderá estender-se além de duzentas milhas marítimas das linhas de base a partir das quais se mede a largura do mar territorial. Embora, na fase inicial da III Conferência das Nações Unidas sobre o Direito do Mar, se esboçasse tendência de unificação entre zona econômica exclusiva e plataforma continental, acabou prevalecendo tendência oposta, a de diversificação entre ambas as áreas. Assim sendo, o limite exterior da plataforma continental, conquanto eventualmente coincida com o mesmo limite da zona econômica exclusiva, pode também ultrapassá-lo na dependência de critérios preponderantemente geológicos. Em razão desses critérios, o limite exterior pode ir até 350 milhas marítimas e mesmo além, nos termos do art. $76 \S 7^{\circ}$, da Convenção das Nações Unidas sobre o Direito do Mar. A plataforma continental não é senão o prolongamento do território terrestre do Estado costeiro, submerso pela zona econômica exclusiva ou mesmo pelo alto-mar. Entre os recursos vivos da plataforma, figuram organismos vivos, como lagostas, pertencentes a espécies sedentárias, ou seja, "aquelas que no periodo de captura estão imóveis no 
leito do mar ou no seu subsolo, ou só podem mover-se em constante contato fisico com esse leito ou subsolo" (Convenção de Montego Bay, art. 77, § $4^{\circ}$ ).

Diferentemente sucede com a zona econômica exclusiva, prolongamento do mar territorial, na qual os recursos naturais a cogitar são preponderantemente biológicos, ou seja, peixe. Nos termos do projeto de acordo das Nações Unidas relativo a peixes transzonais e altamente migratórios, a ser submetido à $6^{a}$ sessão da Conferência respectiva (de 24 de julho a 5 de agosto p.f.), o termo "peixe" inclui moluscos e crustáceos, exceto aqueles pertencentes às espécies sedentárias, como tais definidos no art. 77 da Convenção das Nações Unidas sobre o Direito do Mar.

9. Zona econômica exclusiva e plataforma continental devem ser delimitados mediante linhas indicadas em cartas de escalas adequadas ou em listas de coordenadas geográficas. Exemplar dessas cartas ou listas deve ser depositado junto ao secretário geral das Nações Unidas e, no caso das linhas de limite exterior da plataforma continental, o respectivo exemplar deve ser depositado junto ao secretário geral da Autoridade dos Fundos Oceânicos, organismo esse cuja sede se instalaria em Kingston, na Jamaica. Previu a Convenção das Nações Unidas sobre o Direito do Mar o estabelecimento de uma Comissão de Limites da Plataforma Continental, composta de 21 membros, peritos em geologia, geofísica ou hidrografia, a serem eleitos em reunião dos Estados-Partes para um mandato de cinco anos, eleição esta que deverá ocorrer brevemente, ou seja, até 16 de maio do próximo ano.

A tarefa de delimitação da zona econômica exclusiva brasileira, que alcança a vasta extensão de 3.000 .000 (três milhões) de $\mathrm{km}^{2}$ é relativamente simples, se comparada com a de delimitação da plataforma continental. O limite exterior da zona econômica exclusiva é determinado pela distância de duzentas milhas marítimas das linhas de base, a partir das quais se mede a largura do mar territorial. Tal distância é também levada em conta no traçado do limite exterior de plataforma continental, mas apenas quando a margem continental ficar aquém dessa distância. Em caso contrário (como felizmente, sucede no Brasil), o limite exterior é determinado por outros critérios, que dependem, por exemplo, da espessura das rochas sedimentares ou da localização do pé do talude continental. O encargo de delimitação de plataforma continental em cartas de escalas adequadas ou de listas de coordenadas geográficas significa operação complexa que está hoje sendo executada em consonância com o LEPLAC, programa da Diretoria de Hidrografia e Navegação supervisionada pela CIRM (Comissão Interministerial dos Recursos do Mar). 
10. Terceiros Estados usufruem na zona econômica exclusiva três espécies de liberdades próprias do alto-mar, inadmissíveis no mar territorial, quais sejam a liberdade de navegação, de sobrevôo e de colocação de cabos e ductos submarinos. No âmbito da liberdade de navegação situa-se a operação de navios e aeronaves. Tais liberdades não são porém, absolutas, pois devem levar em conta os direitos e deveres dos Estados costeiros cujas leis e regulamentos, desde que compatíveis com as normas internacionais, terceiros Estados se obrigam a respeitar. Assim é que, como dispõe a lei 8.617, de 04 de janeiro de 1993, promulgada pelo Governo brasileiro, "a realização por outros Estados, na zona econômica exclusiva, de exercícios ou manobras militares, em particular as que impliquem o uso de armas ou explosivos, somente poderá ocorrer com o consentimento desse mesmo governo." (art. $9^{\circ}$ ). O traçado da linha para a colocação de cabos e ductos submarinos depende também do consentimento do Estado costeiro que se reserva o "direito de tomar medidas razoáveis para a exploração da plataforma continental, o aproveitamento de seus recursos naturais e a prevenção, redução e controle da poluição causada por cabos e ductos submarinos" (Convenção das Nações Unidas, art. 79, § $2^{\circ}$, e art. 87, $\left.\S 1^{\circ}, \underline{\mathrm{c}}\right)$.

11. Que direitos possui o Estado costeiro em sua zona econômica exclusiva? São direitos de soberania, os quais não se confundem necessariamente com a própria soberania. Esta é a competência da competência. Exerce-se para todos os fins, nos termos do direito internacional. Os direitos de soberania têm, ao contrário, uma destinação específica. Assim é que o Estado costeiro os tem em relação às ilhas artificiais, instalações e estruturas. Na zona econômica exclusiva, diz a Convenção, o Estado costeiro tem o direito exclusivo de construir e de autorizar e regulamentar a construção, operação e utilização de: a) ilhas artificiais; b) instalação e estruturas. Ele "tem jurisdição exclusiva" (diz a Convenção, art. $60 § 2^{\circ}$ ) "sobre as ilhas artificiais, instalação e estruturas, incluindo jurisdição em matéria de leis e regulamentos aduaneiros, fiscais, de imigração, sanitários e de segurança"

O Estado costeiro tem jurisdição também em relação à investigação científica marinha, que deve ser realizada com seu consentimento tanto na área do seu mar territorial e da sua plataforma continental quanto na área de sua zona econômica exclusiva (art. 246, $\S 1^{\circ}$ ). Em circunstâncias normais, diz a Convenção, ele deve "dar o seu consentimento a outros Estados ou organizações internacionais competentes" para que executem projetos de investigação científica marinha na sua zona econômica exclusiva ou na sua plataforma continental, exclusivamente com fins 
pacíficos e com o propósito de aumentar o conhecimento científico do meio marinho em benefício de toda humanidade ( $a r t .246, \S 2^{\circ}$ ). Tem o Estado costeiro igualmente direitos de soberania referentes a atividades "com vista à exploração $e$ aproveitamento da zona para fins econômicos, como a produção de energia a partir da água, das correntes e dos ventos".

12. Na zona econômica exclusiva, com relação a recursos naturais, vivos ou não-vivos das águas sobrejacentes ao leito do mar e de seu subsolo, o Estado costeiro possui direitos de soberania, para fins de exploração e aproveitamento, conservação e gestão dos recursos (Convenção, art. 56). Nenhum terceiro Estado pode explorar recursos naturais da zona econômica exclusiva sem anuência do Estado costeiro. Essa a razão dos adjetivos "exclusiva" e "econômica" que se incluem na denominação dessa zona. No exercício desses direitos, o Estado costeiro está autorizado a tomar as medidas necessárias, sendo que, "nos casos de apresamento ou retenção de embarcações estrangeiras" ele deve, pelos canais apropriados, "notificar sem demora o Estado de bandeira das medidas tomadas e das sanções ulteriormente impostas" (Convenção, art. 73, § $4^{\circ}$ ).

Em seu mar territorial, o Estado exerce soberania, ou seja, um poder incontrastável semelhante ao exercido no território terrestre (limitado apenas, como se disse, pelo reconhecimento do direito de passagem inocente de navios estrangeiros). Tais navios têm o direito apenas de transitar, não podendo estacionar, ancorar. A passagem deve ser também inofensiva, não acarretando prejuízos ao Estado costeiro. Estão esses navios impedidos, pois, de exercer a pesca. A soberania é exercida para todos os fins, nos termos do Direito Internacional. Em sua zona econômica exclusiva e em sua plataforma continental, o Estado exerce direitos de soberania, ou seja, direitos de um poder incontrastável, porém endereçados para determinados fins. No concernente aos recursos naturais, o primeiro desses fins vem a ser o da exploração, do conhecimento, da identificação, da classificação e da avaliação do potencial desses recursos. São direitos, pois, que correspondem a deveres precisos. Como decorrência dessa finalidade primeira, surgem os demais. Os direitos soberanos são exercidos também para fins de conservação, de gestão ainda, principalmente, para fins de utilização (aproveitamento dos recursos naturais). A utilização desses recursos, diz a Convenção (art. 62), deve ser ótima, ou seja a melhor possível. Ora, não se poderia alcançá-la a não ser mediante o conhecimento desses recursos, a conservação desses recursos, a gestão desses recursos. 
13. Em sua zona econômica exclusiva, incumbe ao Estado costeiro fixar "as capturas permissiveis" "Tendo em conta os melhores dados cientificos de que disponha, assegurará, por meio de medidas apropriadas de conservação $e$ gestão, que a preservação dos recursos vivos de sua zona econômica exclusiva não seja ameaçada por um excesso de captura" (Convenção, art. $62 \S 1^{\circ}$, art. $61 \S \S 1^{\circ} \mathrm{e}$ $2^{\circ}$ ). "Tais medidas devem ter também a finalidade de preservar ou restabelecer a população das espécies capturadas a niveis que possam produzir o máximo rendimento constante, determinado a partir de fatores ecológicos e econômicos pertinentes, incluindo as necessidades econômicas das comunidades costeiras que vivem da pesca e as necessidades especiais dos Estados em desenvolvimento, $e$ tendo em conta os métodos de pesca, a interdependência das populações $e$ quaisquer outras normas mínimas internacionais geralmente recomendadas" (Convenção, art. 61, $\S 3^{\circ}$ ). Tais disposições do tratado de Montego Bay correspondem ao núcleo do conceito de desenvolvimento_sustentável explicitado na Agenda XXI da Conferência das Nações Unidas sobre Meio Ambiente e Desenvolvimento, reunida há alguns meses, no Rio de Janeiro, e incorporado ao projeto de convenção sobre espécies transzonais e espécies altamente migratórias. $\mathrm{O}$ programa "Avaliação do Potencial Sustentável de Recursos Vivos na Zona Econômica Exclusiva" de 1994, inserido no contexto dos objetivos definidos pelo IV Plano Setorial para os Recursos do Mar, concebido com base no Programa Revizee, elaborado quatro anos antes, no âmbito de CIRM, lembra casos de excesso de capturas ocorridos a partir da década de 70, certamente por desconhecimento de dados científicos sobre o potencial de nossos recursos pesqueiros. "Dentre os recursos mais afetados" diz aquela Avaliação, "destacam-se a sardinha, os camarões e peixes demersais do Sudeste/Sul, lagosta e piramutaba. O exemplo da sardinha é particularmente crítico, pois de uma produção máxima de 228 mil toneladas, 1973, quando existiam mais de 400 embarcações em atuação e reduziuse numa produção de apenas 32 mil toneladas em 1990".

$\mathrm{O}$ desconhecimento do potencial de recursos ictiológicos acarreta conseqüência oposta, também deplorável, o da utilização nula ou insuficiente desses recursos, pecado gravíssimo num país como o nosso, subdesenvolvido, de população assolada pela miséria e pela fome.

14. Retomemos, porém, a pergunta inserida no tópico desta palestra: vamos perder as duzentas milhas? 
A resposta comporta distinções. De fato, a expressão "duzentas milhas" alcança duplo significado. O primeiro se refere a determinado espaço marítimo, no qual localizam quatro áreas distintas, cada qual com natureza, delimitação e regime próprios. Algumas dessa áreas são parte integrante do Estado costeiro, prolongamento necessário no território terrestre, a que esse Estado não pode renunciar. Outras dessas áreas, sim, e no caso vertente, se trata especificamente da zona contígua, o Estado pode dispensá-la. Trata-se de área na qual o Estado costeiro se incumbe de medidas de interesse alfandegário, fiscal e sanitário. Não se pode e nem se deve, todavia, dispensar o mar territorial, à plataforma continental e à zona econômica exclusiva, partes integrantes do espaço do Estado costeiro. Por conseguinte, não vamos jamais perder as duzentas milhas.

15. Outro significado da expressão "duzentas milhas" refere-se aos recursos naturais nelas existentes e tem pertinência com um dos catorze objetivos consignados na Política Marítima Nacional (Decreto n. 1.265, de 11 de outubro de 1994). Nesse sentido, a rigor, não apenas corremos o risco de perdê-las como já, infelizmente, de há muito, estamos a perdê-las, malgrado iniciativas louváveis pungidas, cá e acolá, de ordem pública, de ordem privada. É preciso contudo, ampliar, reproduzir, acelerar tais iniciativas, em conformidade aliás com o propósito governamental de privilegiar o atendimento das necessidades básicas de nosso povo. Urge inventariar as riquezas naturais, determinar-lhes a biomassa, estabelecer e aprimorar os potenciais de captura, promover o detalhamento geográfico, geológico e ictiológico das pesquisas. Requerem-se instrumentos de medição precisa das propriedades bióticas e abióticas do meio marinho, capacitação daas disponibilidades técnicas e humanas, embarcações providas de tecnologia avançada, estímulo a investigação no campo ca oceanografia, física, química, biológica, geológica, inclusive com emprego de sensoriamento remoto.

Estamos a perder efetivamente recursos naturais das duzentas milhas à medida que não os conhecemos suficientemente, que as pesquisas científicas prossigam restritas e incompletas. Condenados a perder esses recursos, estamos a perder a nós mesmos, povo sofrido e faminto, carente de proteínas, subdesenvolvido, condenado paradoxalmente a contemplar, ao longo do litoral, tesouro inestimável de recursos a esvair-se, dia após dia, na seqüência implacável do tempo. Entre as duzentas milhas marítimas e o programa do combate à fome ou da ação da cidadania contra a miséria e pela vida há vínculos sistemáticos a estabelecer, almejados por todas as pessoas de boa-fé e de propósitos construtivos. Esse programa tem sido 
adstrito à produção terrestre e, nesse sentido, relacionado com a temática da reforma agrária. Mister se faz, porém, vinculá-lo também urgentemente à exploração e explotação das riquezas naturais dos espaços marítimos sujeitos à jurisdição nacional. 